\title{
Physical, Mechanical, and Morphological Properties of Woven Kenaf/Polymer Composites Produced Using a Vacuum Infusion Technique
}

\author{
Suhad D. Salman, ${ }^{1,2}$ Mohaiman J. Sharba, ${ }^{1,3}$ Z. Leman, ${ }^{1}$ M. T. H. Sultan, ${ }^{4}$ \\ M. R. Ishak, ${ }^{4,5}$ and F. Cardona ${ }^{4}$ \\ ${ }^{1}$ Department of Mechanical and Manufacturing Engineering, Faculty of Engineering, Universiti Putra Malaysia, \\ 43400 Serdang, Selangor, Malaysia \\ ${ }^{2}$ Materials Engineering Department, Faculty of Engineering, The University of Mustansiriyah, Baghdad, Iraq \\ ${ }^{3}$ Mechanical Engineering Department, Al Suwayrah Technical Institute, Middle Technical University, Baghdad, Iraq \\ ${ }^{4}$ Aerospace Manufacturing Research Centre (AMRC), Level 7, Tower Block, Faculty of Engineering, UPM, 43400 Serdang, \\ Selangor, Malaysia \\ ${ }^{5}$ Laboratory of Bio-Composites Technology, Institute of Tropical Forestry and Forest Products (INTROP), \\ Universiti Putra Malaysia (UPM), 43400 Serdang, Selangor, Malaysia
}

Correspondence should be addressed to Suhad D. Salman; suhaddawood2007@yahoo.com

Received 29 January 2015; Revised 4 April 2015; Accepted 25 April 2015

Academic Editor: Mahbub Hasan

Copyright (C) 2015 Suhad D. Salman et al. This is an open access article distributed under the Creative Commons Attribution License, which permits unrestricted use, distribution, and reproduction in any medium, provided the original work is properly cited.

Nowadays, due to renewable issues, environmental concerns, and the financial problems of synthetic fibres, the development of high-performance engineering products made from natural resources is increasing all over the world. Lately, kenaf fibre has been used among many different types of natural resources in various shapes. Unidirectional long fibres or randomly oriented short fibre shapes are the most common type of kenaf fibres that have been investigated in previous works. This work characterises and evaluates the physical, mechanical, and morphological properties of plain woven kenaf fabric and its composites with three types of thermoset resin at $0^{\circ} / 90^{\circ}$ and $45^{\circ} /-45^{\circ}$ orientation, in order to assess their suitability as lignocellulosic reinforced polymer composites. A vacuum infusion manufacturing technique was used to prepare the specimens with fibre weight content of $35 \% \pm 2 \%$. Eight specimens were prepared for each test, and five replications were adopted. A total of 78 samples were tested in this study. The results show that the composites with $0^{\circ} / 90^{\circ}$ had the highest tensile, flexural strengths, and modulus. The morphological properties of composite samples were analysed through scanning electron microscopy (SEM) images and these clearly demonstrated the better interfacial adhesion between the woven kenaf and the epoxy matrix.

\section{Introduction}

In the past two decades a number of researchers have sought to use natural fibres with a polymer matrix composite (PMC); this has received considerable attention both in the literature and the industry. Although synthetic fibres such as Kevlar, glass, and carbon are extensively used for the reinforcement of plastics, these materials are expensive and are nonrenewable resources $[1,2]$. Many of the woven natural fabrics are rising as a viable option to glass fibre reinforced composites in industrial applications like packaging, paper making, and composite materials. One of the more popular natural fibres is kenaf fibre, which is an annual plant due to its rapid growth, and has an average yield of $1700 \mathrm{~kg} / \mathrm{ha}[3,4]$. Kenaf fibre is produced from the bast of the stems of plants of genus Hibiscus, a family of Malvaceae, and species of cannibinus. It requires less water to grow. Kenaf fibres have the advantage that they are renewable resources, low cost, light, plentiful, nonabrasive, and nonhazardous. Therefore they can serve as an excellent reinforcing agent for plastics [5]. Kenaf fibre 


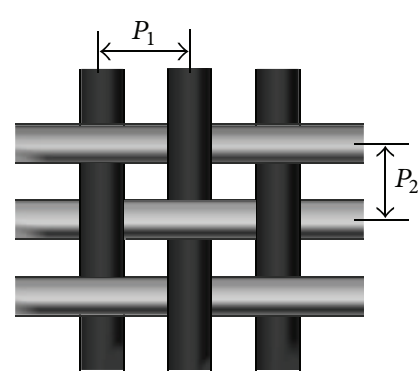

(a)

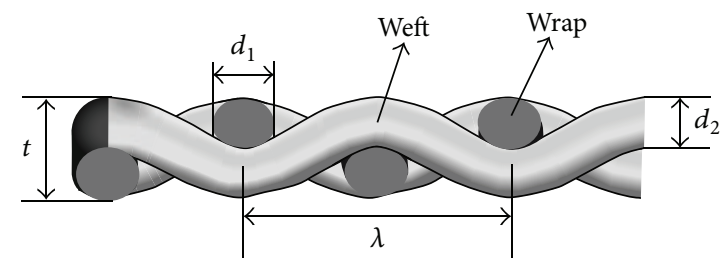

(b)

FIgURE 1: Plain woven fabric: (a) top view and (b) cross section view [7].

possesses moderately high specific strength and stiffness and can be utilised as a reinforcing material in polymeric resins to make a useful structural composite material. Kenaf has already been adopted in automobile parts due to its light weight and good mechanical properties [6].

Woven fabrics are formed, in particular, by the interlacing of fibre bundles (yarns) to form a fabric layer, which offers advantages in terms of good dimensional stability and high packing density [7]. The vertical yarn direction is called the warp while the horizontal yarn direction is called the weft as shown in Figure 1. The use of the plain weave technique can add structural strength to the material because it increases both the strength and the energy absorption capacity. Woven fabrics are used in a wide variety of defence and consumer products as the reinforcement phase of composites due to their flexibility, formability, and high specific strength because the interlocking increases strength better than fibre matrix adhesion [8]. Yarn slip, the relative sliding of the yarns composing the weave, is an important mode of deformation or failure, which leads to dramatic changes in the energy absorption and yarn density of the fabric. The use of a woven fabric pattern could add structural strength because it increases the strength and energy absorption capacity of the material.

Figure 1 illustrates a plain weave fabric. $P_{1}$ and $P_{2}$ represent the distance between warp and weft yarns, while $d_{1}$ and $d_{2}$ denote the warp and weft yarn circular diameter. $t$ represents the fabric thickness (measured by a digital caliper), whilst $\lambda$ indicates the fabric wavelength. The weave of the fabric is characterised by thickness, weight, density, wavelength, and interyarn fabric porosity $(\varepsilon)$. Using (1), the interyarn fabric porosity $(\varepsilon)$ was calculated. The ratio of the projected geometrical area of the opening across the material to the total area of the material is the definition of porosity $[9,10]$ :

$$
\varepsilon=\frac{\left(P_{1}-d_{1}\right)\left(P_{2}-d_{2}\right)}{\left(P_{1} \times P_{2}\right)} .
$$

The experimental investigation of the crashworthiness characteristics of kenaf fabric (mat) reinforced polyester (KFRP) circular tubes from the point of view of energy absorption, with different geometry, was carried out by Ibrahim [11]. It was found that geometry was an important factor to determine the ability of a material to absorb energy. Furthermore, a thin-walled tube has a good geometry for a high strength to weight ratio and energy absorption capability. In another major study, the tensile and flexural strengths of the unidirectional kenaf fibre reinforced poly lactic acid (PLA) resin composites were investigated by Ochi [12] with different fibre content. Experimental results showed that the weight of composites increased linearly up to a fibre content of $50 \%$.

In recent years, the effects of chemical treatments on the tensile and flexural properties of the short kenaf polypropylene composites were investigated by Asumani et al. [13]. Mechanical test results showed that the improvements in the tensile and flexural properties resulting from alkali silane treatment were due to the better bonding between the fibres and the polymer. Several attempts have been made to study the influence of fibre content on the mechanical and thermal properties of kenaf bast fibre reinforced thermoplastic polyurethane (TPU) composites with different fibre loadings (by El-Shekeil et al. [14, 15]). It was concluded that a 30\% fibre loading displayed the best tensile strength, whilst the tensile modulus, thermal stability, hardness, and flexural strength increased with the increase of fibre content, but the strain value decreased with increasing of fibre content.

The mechanical properties of a nonwoven kenaf fibre composite and poly-L-lactic acid (PLLA) resin were investigated by Nishino et al. [16]. It was reported that kenaf fibre could be a good candidate for use as a reinforcing fibre for high performance polymer composites. In another study, Salleh et al. [17] found that processing at high temperature leads to an improvement in the tensile modulus of composites, in contrast with the diminished properties when processed at low temperatures especially with high fibre content. Furthermore, with the increased content of the fibre, the tensile strength and strain of the composite decreased when using low and high processing temperatures. It was also reported that a scale ratio between reinforcements of different aspect ratios may play a role as a controlling factor in optimising the mechanical properties of a composite material [18-20].

Another crucial factor is the kenaf fibre orientation, which has a significant effect on the mechanical behaviour of composite materials [21]. It was reported that the composite's properties were influenced by changing the fibre orientation. Chow et al. [22] studied the effect of weaving patterns and 
TABle 1: Physical and mechanical properties of polymers (manufacturer data sheet).

\begin{tabular}{|c|c|c|c|c|c|}
\hline Polymer & $\begin{array}{l}\text { Density } \\
\left(\mathrm{g} / \mathrm{cm}^{3}\right)\end{array}$ & $\begin{array}{c}\text { Tensile strength } \\
(\mathrm{MPa})\end{array}$ & $\begin{array}{c}\text { Elastic modulus } \\
(\mathrm{MPa})\end{array}$ & $\begin{array}{c}\text { Elongation at } \\
\text { break }(\%)\end{array}$ & Hardener \% \\
\hline Epoxy LY556 & 1.14 & 73.3 & 3470 & 4.5 & $1: 2$ [HY951] \\
\hline Unsaturated polyester & 1.14 & 69 & 3800 & 2.3 & $0.2[\mathrm{MEKP}]$ \\
\hline Vinyl ester & 1.14 & 86 & 3200 & $5-6$ & 0.2 \\
\hline
\end{tabular}

random orientation on the mechanical properties of banana, kenaf, and banana/kenaf fibre-reinforced hybrid polyester composites. Plain and twill weaving patterns were used to fabricate the composite; the plain type showed improved tensile properties compared to the twill type. Moreover, the maximum increase in mechanical strength was observed in the plain woven hybrid composites rather than in randomly oriented composites, which lead to minimum stress development at the interface of composites because of the distribution of load transfer along the fibre direction.

Even though kenaf fibres have the potential to supplement synthetic fibres in polymer composites [23], limitations arise with respect to mechanical performance and moisture absorption when natural fibres are used [24, 25]. In this study, achieving the advantages of kenaf fibres and the woven pattern has been considered. Besides this, the prediction of the mechanical properties of composites has many advantages when components are changed in volume or type, as it does not need additional measurements in order to know their mechanical properties. Consequently, this paper aims to determine the physical, mechanical, and morphological properties. A discussion based on the data collected from the literature is also given in order to create a brief guideline for future development concerning the use of woven kenaf fibres.

\section{Materials and Methods}

In order to study the behaviour of woven kenaf fibres with three types of polymers on the mechanical properties of composites, the fibre density, fibre diameter, fibre length, moisture content, water absorption, and porosity of woven kenaf fibres are measured.

Kenaf fibre is the main fibre used in this study and was supplied by ZKK Sdn. Bhd., Malaysia (as shown in Figure 1). The physical and mechanical properties of kenaf yarn were measured according to the ASTM D3379-10 standard [26]. The plain woven kenaf fibre was prepared and cut to fabricate composite samples according to the ASTM standards. Three types of thermoset resins were used to fabricate the composite samples, namely, epoxy, unsaturated polyester, and vinyl ester resin. The properties of the three types of polymers are shown in Table 1 (manufacturer data sheet).

The kenaf fibre density was obtained using mathematical equation (2) by dividing the mass by the volume, according to the ASTM D 1895 standard [27]. Kenaf fibre was put into a container with a known volume $\left(V_{c}\right)$. The weight of the container was weighed and recorded as $M_{c}$ and the kenaf filled container was weighed and labeled as $M_{k}$ :

$$
\text { Density } \rho\left(\mathrm{g} / \mathrm{cm}^{3}\right)=\frac{M_{k}-M_{c}}{V_{c}} \text {. }
$$

Both the diameter and the length of the kenaf fibre were measured using an optical microscope and digital caliper. Twenty kenaf fibre yarns were tested and the average value of the diameter and length was recorded.

All types of polymer composites will absorb moisture from the surrounding area to a certain extent when immersed in water or exposed to a humid environment [28]. It is not only the polymer matrix that absorbs moisture, but also the fibre, especially natural fibre, due to its hydrophilic nature. It is more sensitive towards water absorption, which causes instability in the properties of the composites [29].

The moisture content specimens were cut according to ASTM D 5229-04 [30] and weighed using an electronic balance of $0.00001 \mathrm{~g}$ accuracy to monitor the mass during the aging process. The specimen is $50 \times 50 \mathrm{~mm}^{3}$, five specimens were tested, and the average was calculated. The moisture content of woven kenaf fibre was obtained by weighing the kenaf fabric, and the initial weight of the fibres was recorded as $\left(M_{1}\right)$ before the samples were put in the oven at $105^{\circ} \mathrm{C}$ for $24 \mathrm{~h}$. The kenaf fabric was weighed again and recorded as $\left(M_{2}\right)$. The moisture content was determined using

$$
\text { Moisture content }=\frac{M_{1}-M_{2}}{M_{1}} \times 100 .
$$

In recent years, many research studies using a natural fibre and polymer matrix have been conducted. It has been demonstrated that the water absorption affects the performance of natural fibre reinforced composites negatively; therefore it is important to study their behaviour. The rate of the degradation is dependent on temperature and humidity [31], which lead to a significant loss in the mechanical properties of natural fibre based composites, especially kenaf fibre reinforced composites, in a humid environment [32]. In one of the largest longitudinal studies, Rassmann et al. [33] investigated the effect of water absorption on the mechanical properties of unwoven kenaf mat. It showed that the composite properties were influenced greatly by immersion in water.

In this study, plain woven kenaf fibre was immersed in water, and the water absorption behaviour was evaluated according to the ASTM D5229 standard [34]. Water absorption was measured after the immersion of the kenaf weave specimens in water at room temperature for 24 hours. Five specimens of kenaf fabric were weighed before and after 


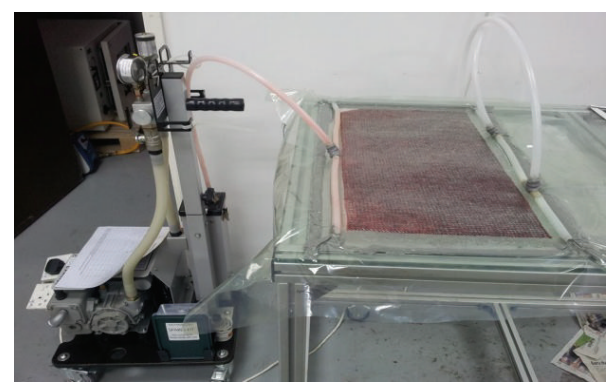

FIGURE 2: The composite specimen using vacuum infusion technique.

immersion, then the water absorption was determined using the following equation:

$$
\text { Water absorption }(\%)=\frac{M_{1}-M_{0}}{M_{0}} \times 100 \text {, }
$$

where $M_{1}$ is the mass of the sample after immersion (g) and $M_{0}$ is the mass of the sample before immersion $(\mathrm{g})[35,36]$.

The composite samples were made with $35 \%$ fibre weight content and the rest for any one of three types of polymers: woven kenaf fibre reinforced epoxy composite (KFRE), woven kenaf fibre reinforced polyester composite (KFRP), and woven kenaf fibre reinforced vinyl ester composite (KFRV). Eight specimens were fabricated for each group using the vacuum infusion technique. The vacuum infusion technique provides a number of improvements over traditional methods such as better fibre-to-resin ratio, less wasted resin, very consistent resin usage, and unlimited setup time, and it is cleaner. The first step of the vacuum infusion technique was begun with polishing the glass surface by using wax (releasing agent), and the resin feed spiral was positioned. Thereafter, one layer of woven kenaf fibre was cut, weighed, and positioned on the surface. Then, both the resin feed connector and the vacuum connector were positioned. The first layer of the infusion, the peel-ply layer, was placed, and then the infusion mesh was added. Subsequently, the tape was applied down the vacuum bag, and the resin feed and vacuum hose were connected and sealed. The resin feed pot was set up and the vacuum pump and catch-pot were connected. The vacuum pump was switched on, the air was evacuated, and the vacuum bag was adjusted. Each polymer was mixed with the ratio of its hardener (resin: hardener by weight) according to the manufacturer's specifications. The vacuum pump was switched on, and the resin was infused and flowed evenly onto a distribution medium until it reached the end, as shown in Figure 2. The excess resin flowed into a resin trap. Demoulding the specimens was done after curing at room temperature for 24 hours; then the specimens were stored on a flat surface under room conditions.

In order to study the mechanical properties of the three types of woven kenaf reinforced polymers, tensile, flexural, and impact and scanning electron microscopy (SEM) tests are performed. Tensile tests of both the kenaf yarn and the plain woven kenaf composite for three types of polymers are investigated.
The strength of the kenaf yarn (weft and warp) was obtained using the universal testing machine with a capacity of $2.5 \mathrm{KN}$ in accordance with ASTM D3379-10, [26]. The crosshead speed was $1 \mathrm{~mm} / \mathrm{min}$ with a replication of 25 times. The fibre was randomly selected, then attached and glued to a tab shaped piece of cardboard, with a gauge length of $170 \mathrm{~mm}$, and then tested.

Tensile testing was carried out in the composite laboratory of the Mechanical Department, Universiti Putra Malaysia, according to the ASTM D3039 standard [37]. All specimens were cut to the $250 \mathrm{~mm} \times 25 \mathrm{~mm} \times$ actual thickness in two angles $0^{\circ} / 90^{\circ}$ and $45^{\circ} /-45^{\circ}$ for each composite and rectangular sectional area flat strip and gage length of $170 \mathrm{~mm}$. Four-tab plates with a dimension of $40 \times 25 \mathrm{~mm}$ were attached to the two sides of both ends of the specimens by an adhesion agent. The test was conducted using a universal testing machine with a capacity of $100 \mathrm{KN}$ and crosshead speed $1 \mathrm{~mm} / \mathrm{min}$, with a replication of 8 times. The average value of the results for the five specimens was taken.

The flexural tests of the woven kenaf fibre composites were investigated using the three-point bending fixture according to the ASTM D-790 standard [38], with a crosshead speed of $1 \mathrm{~mm} / \mathrm{min}$. The rectangular shape three-point bending specimens were prepared with dimensions of $127 \mathrm{~mm} \times$ $12.7 \mathrm{~mm} \times$ actual thickness in two angles $0^{\circ} / 90^{\circ}$ and $45^{\circ} /-45^{\circ}$ for each composite. The distance between the supports (span length) was calculated as per the standard, with a ratio of $16: 1$. For each case, eight specimens were tested and the average values of the five specimens were recorded.

The impact strength of the samples was measured using an Izod impact test machine, according to the ASTM 256 standard [39]. The standard specimens size was $63.5 \mathrm{~mm} \times$ $12.7 \mathrm{~mm} \times$ actual thickness in two angles $0^{\circ} / 90^{\circ}$ and $45^{\circ} /-45^{\circ}$ for each composite and notched by motorised notchvis. All impact test samples were supported as a vertical cantilever beam and broken by a single swing of a pendulum, with hammer velocity $6 \mathrm{~m} / \mathrm{s}$. For each case, eight specimens were tested and the average value of five results was recorded.

Using the scanning electron microscope (SEM) instrument model ZEISS SUPRA 35VP, the fracture surface of the specimen after the tensile test was observed. All the fractured specimens were coated with a thin layer of gold, to avoid electron charge accumulation, and subjected to a voltage of $10-15 \mathrm{kv}$.

\section{Results and Discussions}

Not only the physical results of the woven kenaf fibres, but also the mechanical properties of the woven kenaf composites are reported and discussed. In addition, the scanning electron microscopy (SEM) images for the tensile specimens test are analysed.

The characteristics of individual fibres vary according to their shapes, sizes, and orientations, and the thickness of the cell walls. Some important physical elements must be known about each plantation fibre before it is used to reach the maximum potential [40]. The fibre length and diameter are the important parameters to determine the strength of natural fibre $[41,42]$. The fibre's strength is an important 
TABle 2: (a) Properties of kenaf yarns. (b) Properties of plain weave kenaf fabric.

(a)

\begin{tabular}{lc}
\hline Properties & Kenaf yarn \\
\hline Yarn fineness (Tex) & 942 \\
Yarn type & 1 ply spun \\
Twist direction & Z-twist \\
Fibre diameter $(\mathrm{mm})$ & $1 \pm 0.1$ \\
Yarn breaking load $(\mathrm{N})$ & 79 \\
Average breaking strength $(\mathrm{MPa})$ & 100.64 \\
Average maximum strain $(\%)$ & 17.3 \\
\hline
\end{tabular}

(b)

\begin{tabular}{lc}
\hline Characterisation & Woven kenaf \\
\hline Thickness, $t(\mathrm{~mm})$ & $2 \pm 0.2$ \\
Weight $\left(\mathrm{g} / \mathrm{m}^{2}\right)$ & 890 \\
Density $\left(\mathrm{g} / \mathrm{cm}^{3}\right)$ & 1.2 \\
Warp density (warp/inch) & 12 \\
Weft density (weft/inch) & 12 \\
Wavelength, $\lambda(\mathrm{mm})$ & 4.2 \\
Interyarn fabric porosity $(\varepsilon)$ & 0.274 \\
Moisture content $(\%)$ & 8.353 \\
Water uptake $(\%)$ & 148.86 \\
\hline
\end{tabular}

factor when choosing a fibre that is specific for a certain usage. Table 2(a) shows the kenaf yarn properties while Table 2(b) shows the physical characterisation of plain woven kenaf. By weighing specified lengths of yarns and converting the data to the Tex unit (according to ASTM D 2260) [43], the yarn fineness was determined. In addition, yarn type and yarn twist direction was also observed. Tensile tests for randomly selected kenaf yarns were measured using the Universal Testing Machine Instron $5 \mathrm{KN}$, with speed $1 \mathrm{~mm} / \mathrm{min}$ and a preload of $2 \mathrm{~N}$. Breaking strength (MPa), breaking strain (\%), and Young's modulus data were recorded.

One of the important parameters that should be considered when choosing natural fibre as a reinforcement in polymer composites is the moisture content. The dimensional stability, electrical resistivity, tensile strength, porosity, and swelling behaviour of natural fibre reinforced composites could be determined by the moisture content [44]. The average value of the moisture content of the woven kenaf was $8.353 \%$ for 5 specimens. While the average water uptake was $148.86 \%$ for 5 specimens after 24 hours. It can be observed that cellulose, which is a major component in kenaf fibre, influences water absorption highly $[45,46]$.

Figures 3 and 4 show the ultimate tensile strength and tensile modulus of woven kenaf composites with three types of polymers, at $0^{\circ} / 90^{\circ}$ and $45^{\circ} /-45^{\circ}$. Among these three types of polymers, epoxy resin shows the highest tensile strength, followed by polyester and vinyl ester, respectively. A similar trend has been reported in the study done by de Albuquerque et al. [47] on jute, where the strain development of the kenaf fibre reinforced composites varied according to the type of resins used. It was observed that there

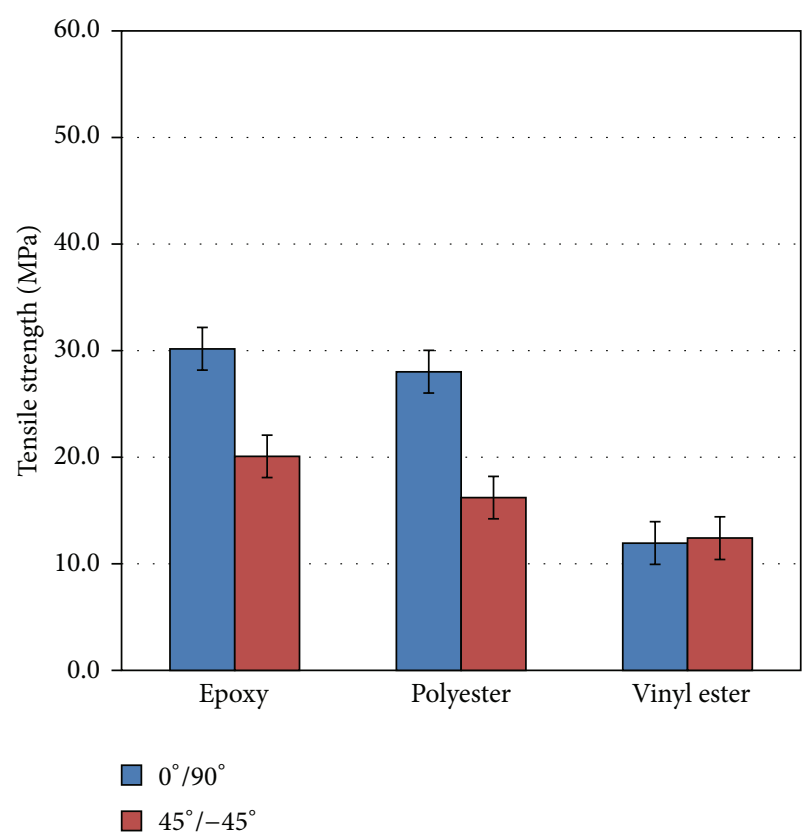

FIGURE 3: Tensile strength of three composites at $0^{\circ} / 90^{\circ}$ and $45^{\circ} /-45^{\circ}$ orientation.

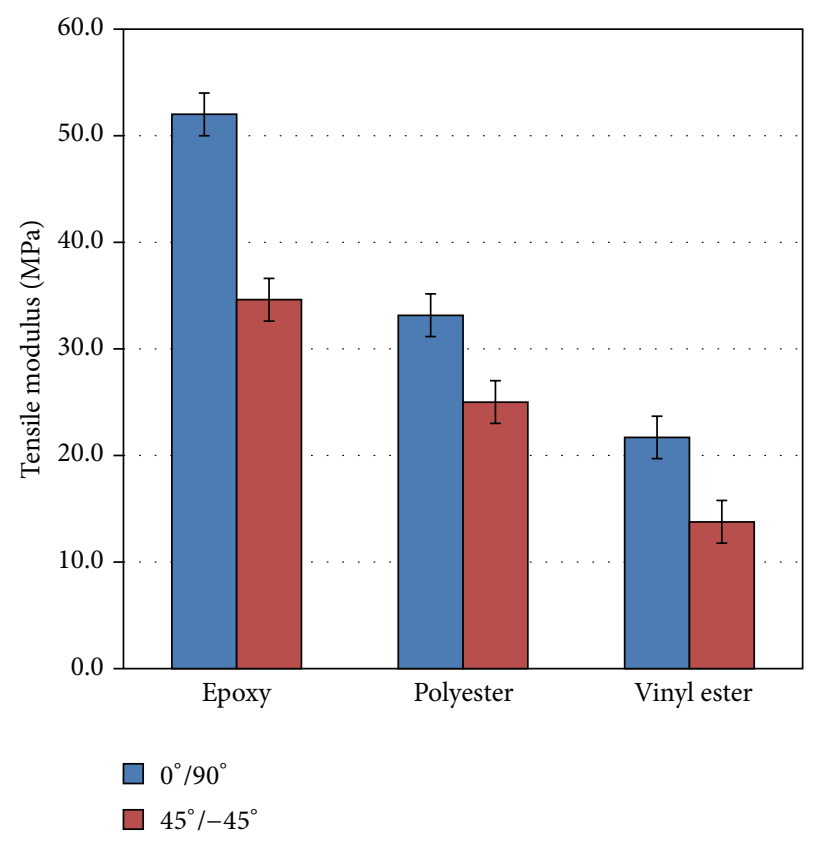

Figure 4: Tensile modulus of three composites at $0^{\circ} / 90^{\circ}$ and $45^{\circ} /-45^{\circ}$ orientation.

was a decline in the tensile properties of the kenaf epoxy and unsaturated polyester composite samples with $45^{\circ} /-45^{\circ}$, while, approximately, there were the same tensile properties for the kenaf vinyl ester composites. This could be due to a uniform distribution of stress transfer with the application of tensile load in both the longitudinal and transverse directions, whereas this is not found in the $45^{\circ} /-45^{\circ}$ orientation. Generally, the increase in the tensile strength and modulus of 


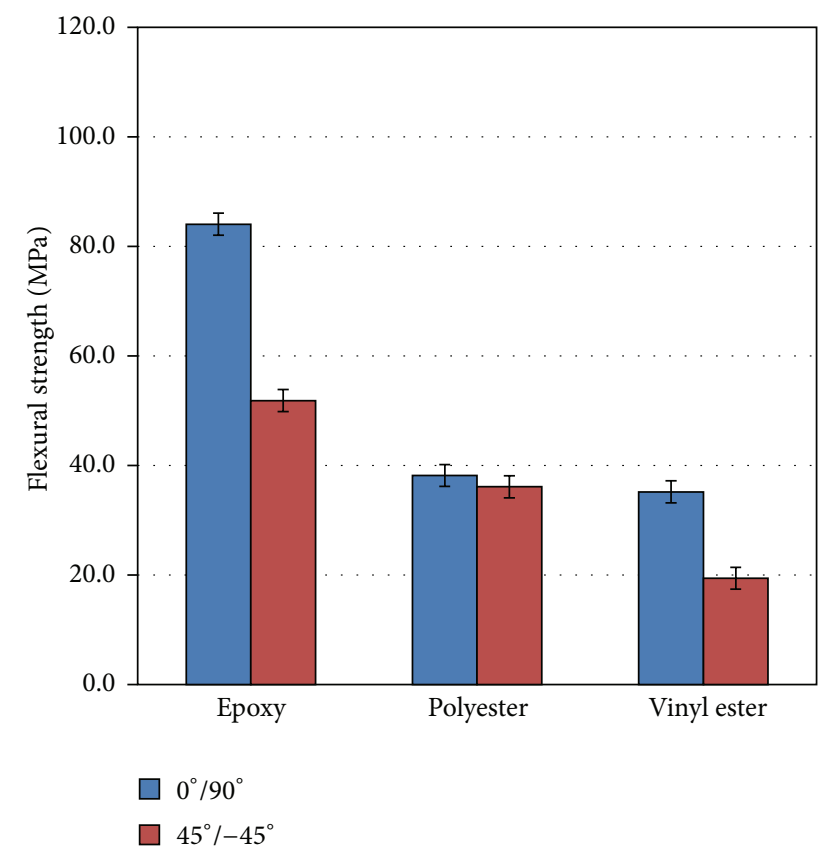

Figure 5: Flexural strength of three composites at $0^{\circ} / 90^{\circ}$ and $45^{\circ} /-45^{\circ}$ orientation.

kenaf composites with $0^{\circ} / 90^{\circ}$ is attributed to the differences in the load-distribution properties of the kenaf fibres along the longitudinal and transverse directions. Thus, $0^{\circ} / 90^{\circ}$ orientation could result in a capacity for greater stress uptake composites which leads to higher mechanical strength. In addition, it can be seen that the values of the tensile modulus of the $0^{\circ} / 90^{\circ}$ orientation are higher than those of the $45^{\circ} /-45^{\circ}$ for the three types of polymers. Furthermore, the epoxy composites had a higher tensile modulus than either the polyester or vinyl ester composites in the $0^{\circ} / 90^{\circ}$ and $45^{\circ} /-45^{\circ}$ orientation as a result of the epoxy bonds to the fibres being better than the polyester and vinyl ester resins. This is in agreement with the findings of Rouison et al. [48] who found similar trends for hemp fibres.

A similar finding was also observed in the flexural strength of the three types of polymers using a 3-point flexural test, as shown in Figures 5 and 6. Like the tensile modulus results, the resin type seems to have a significant influence on the flexural modulus for each of the three types of polymers. The ultimate flexural strength and flexural modulus of woven kenaf composites with epoxy and vinyl ester polymers decreased with $45^{\circ} /-45^{\circ}$, whilst the ultimate flexural strength and modulus of woven kenaf composites with unsaturated polyester was almost the same. In different orientations, the flexural effect of both the fibre yarns in the warp and weft directions can create an interlocking structure which can result in constraints for the extension of the fibre yarns along the directions, resulting in fibres with a higher bending load capacity. As research studies have reported, the flexural properties depend on the type of polymer and fibre orientations are critical factors which have an important influence on the mechanical properties

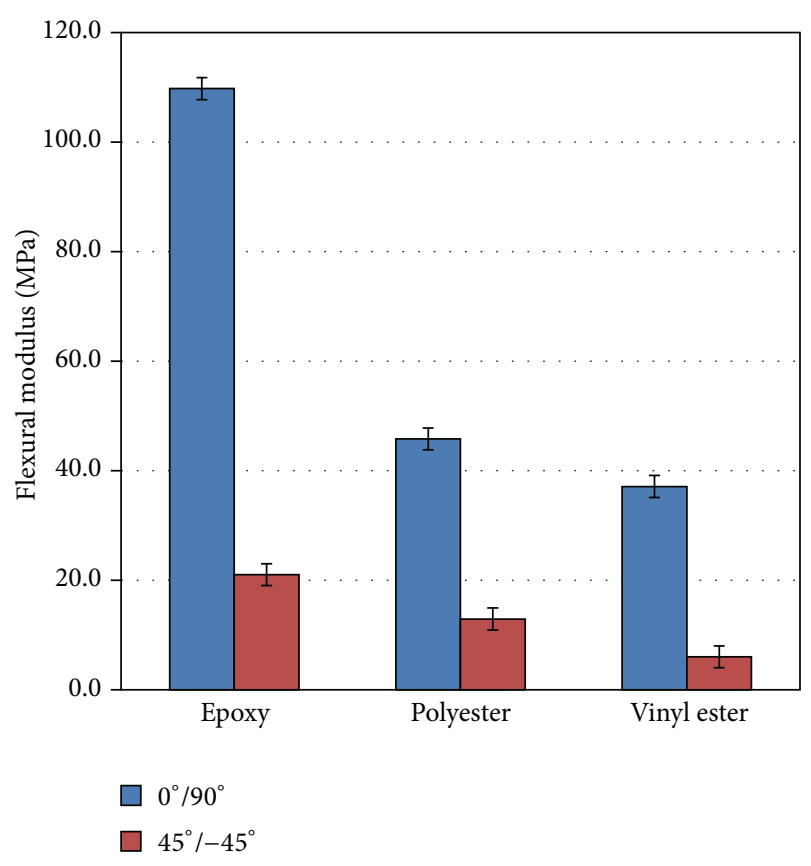

Figure 6: Flexural modulus of three composites at $0^{\circ} / 90^{\circ}$ and $45^{\circ} /-45^{\circ}$ orientation.

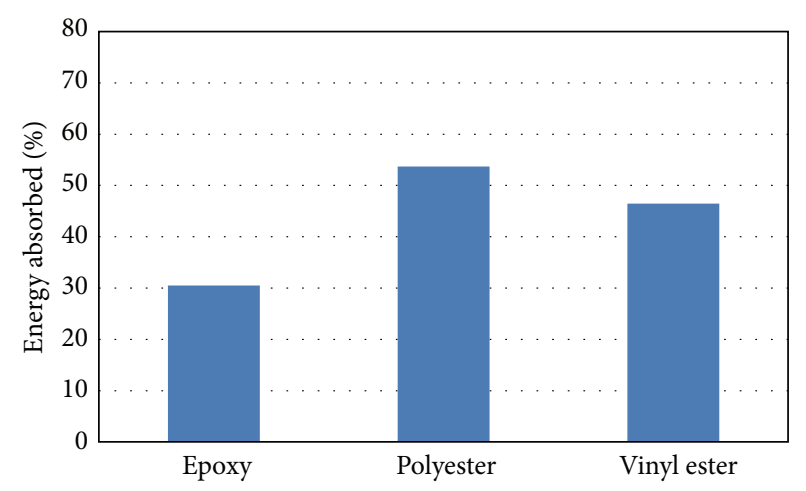

FIGURE 7: Impact strength of three composites at $0^{\circ} / 90^{\circ}$ orientation.

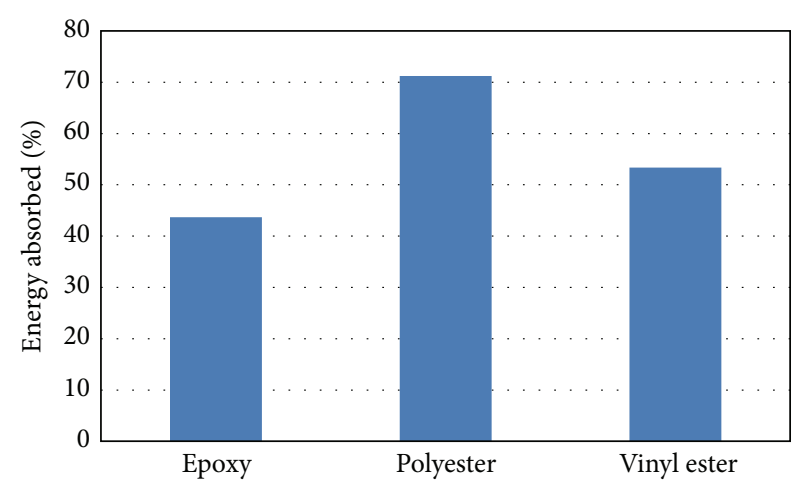

FIGURE 8: Impact strength of three composites at $45^{\circ} /-45^{\circ}$ orientation. 


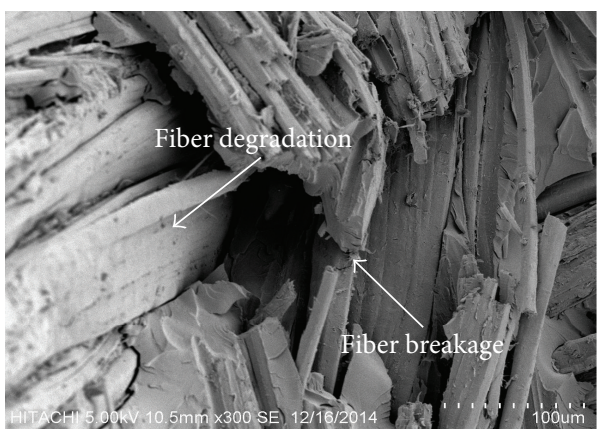

(a)

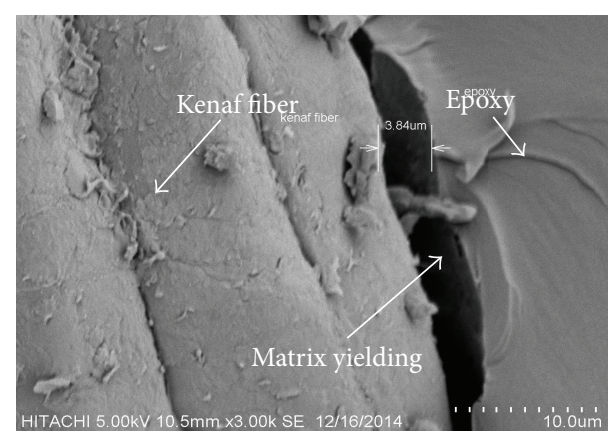

(b)

FIgURE 9: (a) The SEM micrographs of the tensile failure surfaces of KFRE. (b) The strong bonding of the kenaf fibre and the epoxy matrix.

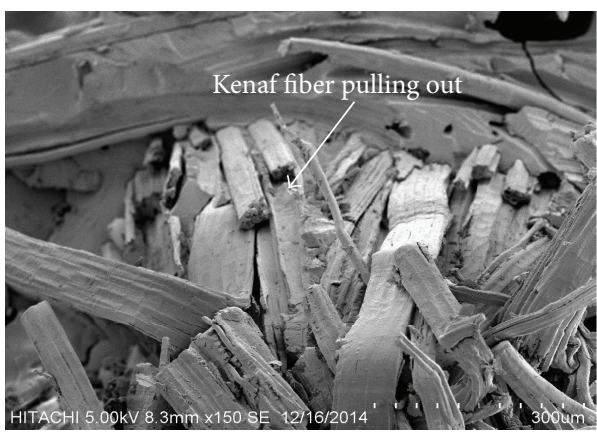

(a)

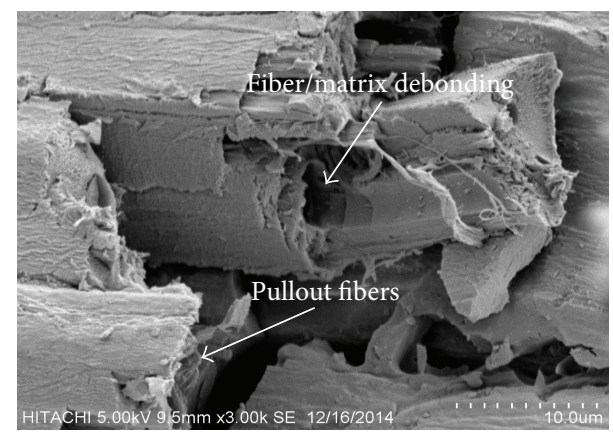

(b)

FIGURE 10: (a) The SEM micrographs of the tensile failure surfaces of KFRP. (b) Bonding area of the woven kenaf with the unsaturated polyester matrix.

of the composites $[49,50]$. It is known that the flexural properties of the composites are also influenced by the composition and adhesion levels of the polymers, that is, the interfacial bonding. Epoxy composites have higher flexural strength and modulus properties compared to other resins, while vinyl ester composites exhibited lower strength values in the different orientations.

The impact strength of woven kenaf composites with three types of polymers, at $0^{\circ} / 90^{\circ}$ and $45^{\circ} /-45^{\circ}$, is presented in Figures 7 and 8 . For the same type of reinforcing fibres, the impact strength of composites differs with the type of polymers. As stated by others [51], the types of polymers, the fibre-matrix interface and the construction and geometry of composites are accountable for deciding the impact strength of composites. It may be observed that kenaf/polyester composites showed the highest energy absorption, while kenaf/epoxy composites exhibited the lowest. It can be concluded that the interfacial strength might have weakened the material causing it to absorb less energy than the other composition as indicated by a number of authors $[17,52]$. The epoxy resin bonds better with the kenaf fibres than the other two polymers. This is an indication of the less fibre pullout and thus a better adhesion between the fibres and the matrix, thus causing a reduction in impact energy with increased fibre matrix adhesion. The kenaf/vinyl ester composites also absorbed a great amount of impact energy. It is clearly seen from Figure 8 that the composites with $45^{\circ} /-45^{\circ}$ orientation have a greater impact strength than composites with $0^{\circ} / 90^{\circ}$ orientation.

3.1. Morphological Properties of WKFC. SEM micrographs confirmed that the mode of failure of epoxy composites was due to fibre fracture, while that of the polyester and vinyl ester composites was due to fibre pullout failure modes. It can also be observed that the epoxy composites display a cleaner failure surface than those made with polyester or vinyl ester composites. This perhaps explains the relatively poor impact strength of epoxy composites, which is an indication of fibre pullout and good fibre matrix adhesion. Figures 9, 10, and 11 show examples of typical SEM micrographs where very few voids were found in the composites, and so a typical micrograph without voids is presented.

\section{Conclusions}

The woven kenaf composite material is fabricated with three types of thermoset matrix to study the mechanical properties with more emphasis. The matrix types used are epoxy, unsaturated polyester and vinyl ester. Plain woven kenaf possesses a good mechanical strength; therefore, it is a good possible candidate to be used as the reinforcement material in polymer composites. The stress-strain diagram of woven kenaf fibre reinforced thermoset composite is linear. The tensile, flexural, and impact strengths of the woven 


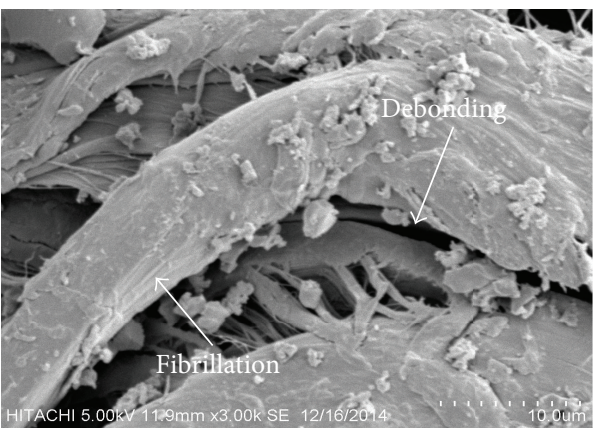

(a)

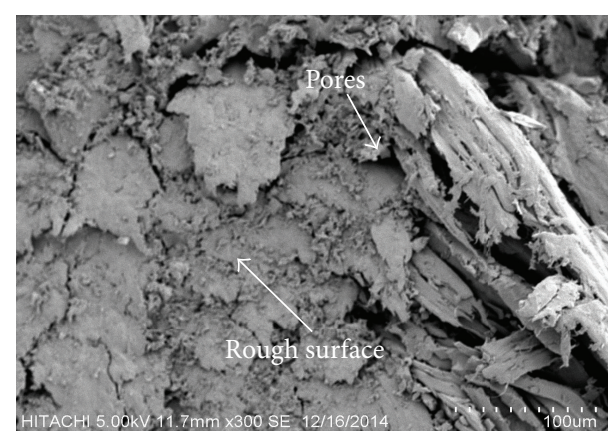

(b)

FIGURE 11: (a) The SEM micrographs of the tensile failure surfaces of KFRV. (b) Bonding area of the woven kenaf with the vinyl ester matrix.

kenaf/epoxy composite are superior to those of the others. Fractography studies of the fracture behaviour of the epoxy composite show that a better fibre-matrix adhesion exists (kenaf fibres were almost broken in the fracture plane). The variation of the mechanical properties, for the same type of thermoset, due to the variation of the fibre orientation, is significant. The results obtained from this study suggest that woven kenaf has higher properties for use as a reinforcement in the thermoset composites sector.

\section{Conflict of Interests}

The authors declare that there is no conflict of interests regarding the publication of this paper.

\section{Acknowledgments}

This work is supported by UPM under GP-IPB Grant 9415402. The authors would like to express their gratitude and sincere appreciation to the Aerospace Manufacturing Research Centre and the Mechanical and Manufacturing Engineering Department of the Universiti Putra Malaysia. The authors' appreciation and gratitude also extend to the Ministry of Higher Education \& Scientific Research of Iraq and to the Material Engineering Department, College of Engineering, and The University of Mustansiriyah for their scientific assistance and financial support.

\section{References}

[1] S. D. Salman, Z. Leman, M. T. H. Sultan, and F. Cardona, "The effect of stacking sequence on tensile properties of hybrid composite," in Proceedings of the Materials Conference: World Research \& Innovation Convention on Engineering \& Technology (WRICET '14), Putrajaya, Malaysia, November 2014.

[2] S. D. Salman, W. S. W. Hassim, and Z. Leman, "Experimental comparison between two types of hybrid composite materials in compression test," in Proceedings of the Conference: Advances in Materials and Processing Technologies (AMPT '14), Dubai, UAE, 2014.

[3] A. R. Khan, "Kenaf, a fiber for future: the Harusmas experience," JEC Composite Magazine, pp. 21-23, 2010.

[4] N. Saba, M. Jawaid, K. Hakeem, M. Paridah, A. Khalina, and O. Alothman, "Potential of bioenergy production from industrial kenaf (Hibiscus cannabinus L.) based on Malaysian perspective," Renewable and Sustainable Energy Reviews, vol. 42, pp. 446-459, 2015.

[5] I. S. Aji, S. M. Sapuan, E. S. Zainudin, and K. Abdan, "Kenaf fibres as reinforcement for polymeric composites: a review," International Journal of Mechanical and Materials Engineering, vol. 4, no. 3, pp. 239-248, 2009.

[6] M. S. Qatu, "Application of kenaf-based natural fiber composites in the automotive industry," in Proceedings of the SAE 2011 World Congress and Exhibition, Detroit, Mich, USA, April 2011.

[7] A. R. A. Hani, M. F. Shaari, N. S. M. Radzuan, M. S. Hashim, R. Ahmad, and M. Mariatti, "Analysis of woven natural fiber fabrics prepared using self-designed handloom," in Proceedings of the International Conference on Mechanical Engineering Research (ICMER '13), Faculty of Mechanical Engineering, Universiti Malaysia Pahang, Pahang, Malaysia, July 2013.

[8] P. Samivel and A. Ramesh Babu, "Mechanical behavior of stacking sequence in kenaf and banana fiber reinforced-polyester laminate," International Journal of Mechanical Engineering and Robotics Research, vol. 2, no. 10, 2013.

[9] A. Çay, R. Atav, and K. Duran, "Effects of warp-weft density variation and fabric porosity of the cotton fabrics on their colour in reactive dyeing," Fibres \& Textiles in Eastern Europe, vol. 15, no. 1, pp. 91-94, 2007.

[10] S. Karimi, P. M. Tahir, A. Karimi, A. Dufresne, and A. Abdulkhani, "Kenaf bast cellulosic fibers hierarchy: a comprehensive approach from micro to nano," Carbohydrate Polymers, vol. 101, no. 1, pp. 878-888, 2014.

[11] T. M. H. B. T. Ibrahim, A study of crashworthiness characteristic of woven kenaf fabric reinforced composites tube [M.S. thesis], Faculty of Mechanical and Manufacturing Engineering, Universiti Tun Hussein Onn Malaysia, 2014.

[12] S. Ochi, "Mechanical properties of kenaf fibers and kenaf/PLA composites," Mechanics of Materials, vol. 40, no. 4-5, pp. 446452, 2008.

[13] O. M. L. Asumani, R. G. Reid, and R. Paskaramoorthy, "The effects of alkali-silane treatment on the tensile and flexural properties of short fibre non-woven kenaf reinforced polypropylene composites," Composites Part A: Applied Science and Manufacturing, vol. 43, no. 9, pp. 1431-1440, 2012.

[14] Y. A. El-Shekeil, S. M. Sapuan, A. Khalina, E. S. Zainudin, and O. M. Al-Shuja'a, "Influence of chemical treatment on the tensile properties of kenaf fiber reinforced thermoplastic polyurethane composite," eXPRESS Polymer Letters, vol. 6, no. 12, pp. 10321040, 2012. 
[15] Y. A. El-Shekeil, S. M. Sapuan, A. Khalina, E. S. Zainudin, and O. M. Al-Shuja'a, "Effect of alkali treatment on mechanical and thermal properties of kenaf fiber-reinforced thermoplastic polyurethane composite," Journal of Thermal Analysis and Calorimetry, vol. 109, no. 3, pp. 1435-1443, 2012.

[16] T. Nishino, K. Hirao, M. Kotera, K. Nakamae, and H. Inagaki, "Kenaf reinforced biodegradable composite," Composites Science and Technology, vol. 63, no. 9, pp. 1281-1286, 2003.

[17] F. M. Salleh, A. Hassan, R. Yahya, and A. D. Azzahari, "Effects of extrusion temperature on the rheological, dynamic mechanical and tensile properties of kenaf fiber/HDPE composites," Composites Part B: Engineering, vol. 58, pp. 259-266, 2014.

[18] H.-J. Kwon, J. Sunthornvarabhas, J.-W. Park et al., “Tensile properties of kenaf fiber and corn husk flour reinforced poly(lactic acid) hybrid bio-composites: role of aspect ratio of natural fibers," Composites Part B: Engineering, vol. 56, pp. 232-237, 2014.

[19] H. J. Kwon, J. Sunthornvarabhas, J. H. Lee, S. Jeon, J. W. Park, and H. J. Kim, "Mechanical properties of kenaf fiber, corn husk flour-filled poly(lactic acid) hybird biocomposites," in Proceedings of the 7th International Workshop on Green Composites (IWGC-7), pp. 38-41, Hamamatsu, Japan, August 2012.

[20] S. B. Brahim and R. B. Cheikh, "Influence of fibre orientation and volume fraction on the tensile properties of unidirectional Alfa-polyester composite," Composites Science and Technology, vol. 67, no. 1, pp. 140-147, 2007.

[21] H. Ku, H. Wang, N. Pattarachaiyakoop, and M. Trada, "A review on the tensile properties of natural fiber reinforced polymer composites," Composites Part B: Engineering, vol. 42, no. 4, pp. 856-873, 2011.

[22] P. Chow, R. J. Lambert, C. Bowers, and N. McKenzie, "Physical and mechanical properties of composite panels made from kenaf plant fibers and plastics," in Proceedings of the 2000 International Kenaf Symposium, pp. 139-143, Hiroshima, Japan, 2000.

[23] F. M. Al-Oqla and S. M. Sapuan, "Natural fiber reinforced polymer composites in industrial applications: feasibility of date palm fibers for sustainable automotive industry," Journal of Cleaner Production, vol. 66, pp. 347-354, 2014.

[24] T. Hojo, Z. Xu, Y. Yang, and H. Hamada, "Tensile properties of bamboo, jute and kenaf mat-reinforced composite," Energy Procedia, vol. 56, pp. 72-79, 2014.

[25] N. Sgriccia, M. C. Hawley, and M. Misra, "Characterization of natural fiber surfaces and natural fiber composites," Composites Part A: Applied Science and Manufacturing, vol. 39, no. 10, pp. 1632-1637, 2008.

[26] American Society of Testing and Materials, Standard Test Method for Tensile Strength and Young's Modulus for HighModulus Single-Filament Materials. ASTM D3379, ASTM International, West Conshohocken, Pa, USA, 2010.

[27] ASTM D1895, Standard Test Methods for Apparent Density, Bulk Factor, and Pourability of Plastic Materials, 2010.

[28] C. P. L. Chow, X. S. Xing, and R. K. Y. Li, "Moisture absorption studies of sisal fibre reinforced polypropylene composites," Composites Science and Technology, vol. 67, no. 2, pp. 306-313, 2007.

[29] M. S. Huda, L. T. Drzal, A. K. Mohanty, and M. Misra, "Effect of fiber surface-treatments on the properties of laminated biocomposites from poly(lactic acid) (PLA) and kenaf fibers," Composites Science and Technology, vol. 68, no. 2, pp. 424-432, 2008.
[30] ASTM, "Standard Test Method for Moisture Absorption Properties and Equilibrium Conditioning of Polymer Matrix Composite Materials," ASTM D 5229/D 5229M-04, 2014.

[31] V. A. Alvarez, A. N. Fraga, and A. Vázquez, "Effects of the moisture and fiber content on the mechanical properties of biodegradable polymer-sisal fiber biocomposites," Journal of Applied Polymer Science, vol. 91, no. 6, pp. 4007-4016, 2004.

[32] H. J. Kim and D. W. Seo, "Effect of water absorption fatigue on mechanical properties of sisal textile-reinforced composites," International Journal of Fatigue, vol. 28, no. 10, pp. 1307-1314, 2006.

[33] S. Rassmann, R. Paskaramoorthy, and R. G. Reid, "Effect of resin system on the mechanical properties and water absorption of kenaf fibre reinforced laminates," Materials and Design, vol. 32, no. 3, pp. 1399-1406, 2011.

[34] ASTM International, Standard Test Method for Water Absorption Properties and Equilibrium Conditioning of Polymer Matrix Composite Materials D5229/D5229M-92, ASTM International, West Conshohocken, Pa, USA, 2014.

[35] H. Chen, M. Miao, and X. Ding, "Influence of moisture absorption on the interfacial strength of bamboo/vinyl ester composites," Composites Part A: Applied Science and Manufacturing, vol. 40, no. 12, pp. 2013-2019, 2009.

[36] Z. Leman, S. M. Sapuan, A. M. Saifol, M. A. Maleque, and M. M. H. M. Ahmad, "Moisture absorption behavior of sugar palm fiber reinforced epoxy composites," Materials and Design, vol. 29, no. 8, pp. 1666-1670, 2008.

[37] ASTM, "Standard test method for tensile properties of polymer matrix composite materials," ASTM D 3039-10:2010, 2010.

[38] ASTM, "Standard test methods for flexural properties of unreinforced and reinforced plastics and electrical insulating materials," ASTM D 790, 2010.

[39] ASTM International, "Standard test methods for determining the Izod pendulum impact resistance of plastics," ASTM D 256, ASTM International, 2010.

[40] G. N. Ramaswamy, T. Sellers, W. Tao, and L. G. Crook, "Kenaf nonwovens as substrates for laminations," Industrial Crops and Products, vol. 17, no. 1, pp. 1-8, 2003.

[41] D. Saravana Bavan and G. C. Mohan Kumar, "Potential use of natural fiber composite materials in India," Journal of Reinforced Plastics and Composites, vol. 29, no. 24, pp. 3600-3613, 2010.

[42] M. Ali, "Coconut fibre-a versatile material and its applications in engineering," in Proceedings of the 2nd International Conference on Sustainable Construction Materials and Technologies, Universita Politecnica delle Marche, Ancona, Italy, June 2010.

[43] ASTM D2260-02, Standard Tables of Conversion Factors and Equivalent Yarn Numbers Measured in Various Numbering Systems.

[44] K. Sukumaran, K. G. Satyanarayana, S. G. K. Pillai, and K. K. Ravikumar, "Structure, physical and mechanical properties of plant fibres of Kerala," Metals Materials and Processes, vol. 13, no. 2-4, pp. 21-136, 2001.

[45] R. M. Rowell, J. S. Han, and J. S. Rowell, "Characterization and factors effecting fiber properties," in Natural Polymers and Agrofibers Composites, E. Follini, A. L. Leao, and L. H. C. Mattoso, Eds., pp. 115-134, Embrapa Instrumentacao Agropecuaria, San Carlos, Brazil, 2000.

[46] A. N. Shebani, A. J. Van Reenen, and M. Meincken, "The effect of wood species on the mechanical and thermal properties of woodg-LLDPE composites," Journal of Composite Materials, vol. 43, no. 11, pp. 1305-1318, 2009. 
[47] A. C. de Albuquerque, K. Joseph, L. H. de Carvalho, and J. R. M. D'Almeida, "Effect of wettability and ageing conditions on the physical and mechanical properties of uniaxially oriented juteroving-reinforced polyester composites," Composites Science and Technology, vol. 60, no. 6, pp. 833-844, 2000.

[48] D. Rouison, M. Sain, and M. Couturier, "Resin transfer molding of hemp fiber composites: optimization of the process and mechanical properties of the materials," Composites Science and Technology, vol. 66, no. 7-8, pp. 895-906, 2006.

[49] M. S. Sreekala, J. George, M. G. Kumaran, and S. Thomas, "The mechanical performance of hybrid phenol-formaldehydebased composites reinforced with glass and oil palm fibres," Composites Science and Technology, vol. 62, no. 3, pp. 339-353, 2002.

[50] H. P. S. Abdul Khalil, A. M. Issam, M. T. Ahmad Shakri, R. Suriani, and A. Y. Awang, "Conventional agro-composites from chemically modified fibres," Industrial Crops and Products, vol. 26, no. 3, pp. 315-323, 2007.

[51] P. V. Joseph, G. Mathew, K. Joseph, G. Groeninckx, and S. Thomas, "Dynamic mechanical properties of short sisal fibre reinforced polypropylene composites," Composites Part A: Applied Science and Manufacturing, vol. 34, no. 3, pp. 275-290, 2003.

[52] G. Sèbe, N. S. Cetin, C. A. S. Hill, and M. Hughes, "RTM hemp fibre-reinforced polyester composites," Applied Composite Materials, vol. 7, no. 5-6, pp. 341-349, 2000. 

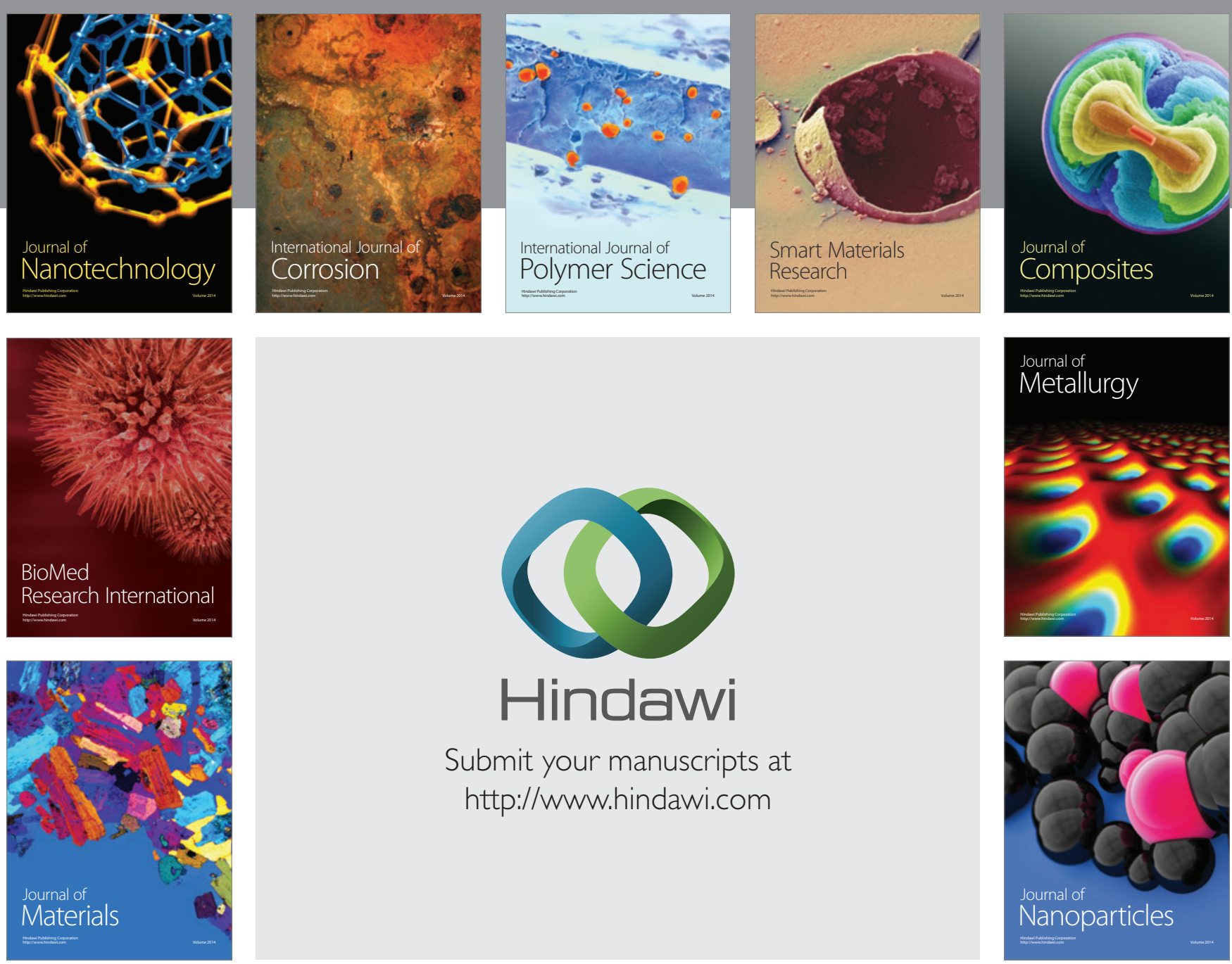

Submit your manuscripts at http://www.hindawi.com
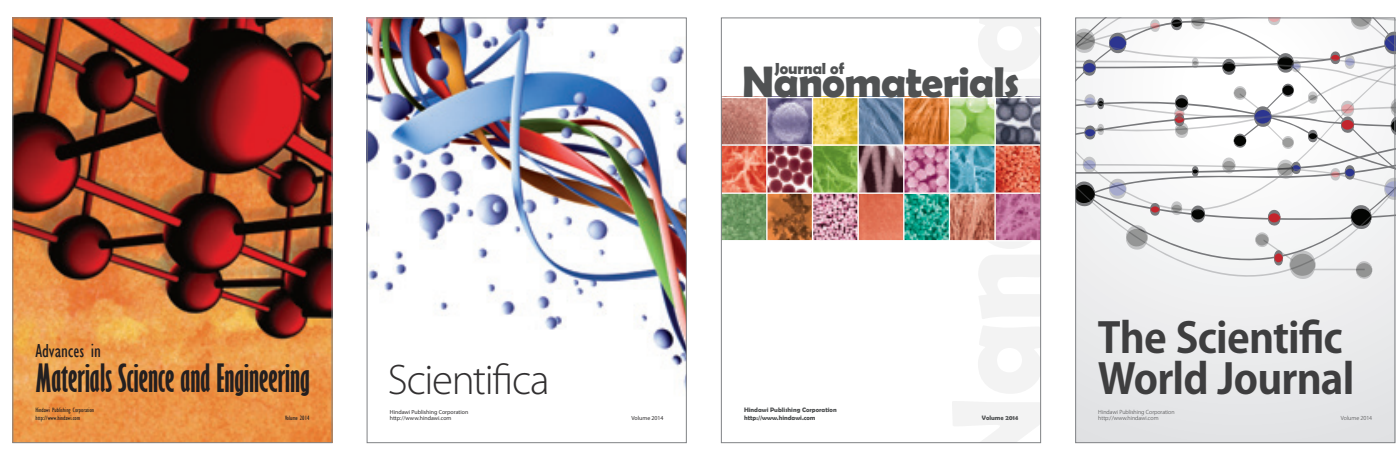

\section{The Scientific World Journal}
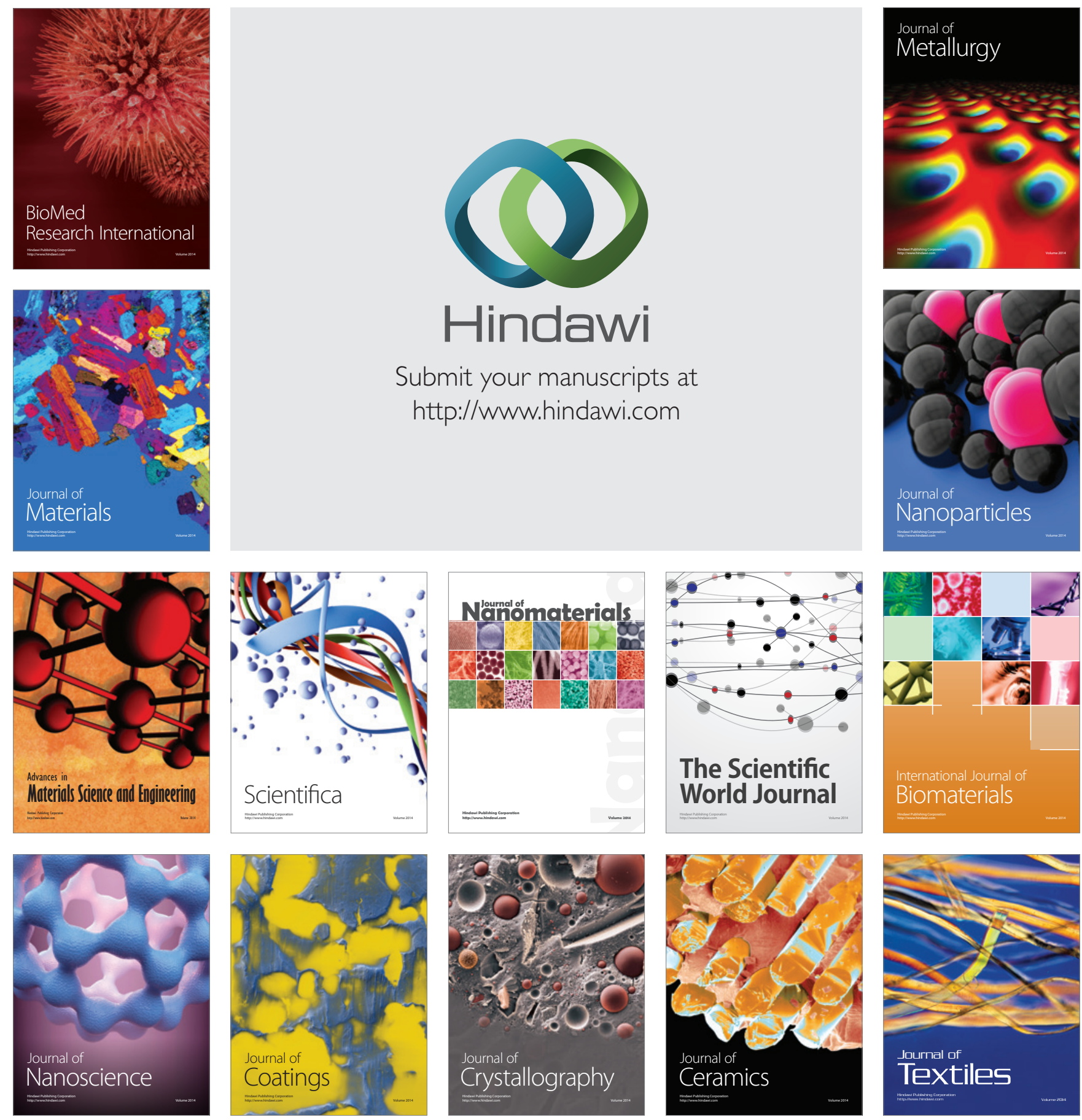